\title{
Procedimentos básicos de seleção de documentos para conversão digital: elementos de atualização profissional em setores de duas instituiçõos públicas federais
}

\author{
Rubens Ribeiro Gonçalves da Silva
}

Dr. em Ciência da Informação (UFRJ/BBCT, 2002); Professor adjunto do Departamento de Fundamentos e Processos Informacionais e do Programa de Pós-Graduação em Ciência da Informação do Instituto de Ciência da Informação da Universidade Federal da Bahia (POSICI/JFBA); Representante do IC//UFBA no Conselho Nacional de Arquivos (CONARQ); Mestre em Antropologia da Arte (EBA/UFRJ); Bacharel licenciado em História (USUL-RJ)

Comenta especificamente os principais elementos da seleção de documentos para digitalização, considerando que mesmo instituições de grande porte enfrentam lacunas na capacitação de seus quadros funcionais. Nesse sentido reúne aspectos observados em assessorias técnicas prestadas ao Centro de Memória e Documentação da Fundação Casa de Rui Barbosa e à Divisão de Informação e Prospecção Tecnológica do Instituto Nacional de Tecnologia, ambas na cidade do Rio de Janeiro. Conclui com considerações acerca do acesso remoto digital a acervos de instituições públicas.

Palavras-chave: Digitalização; Seleção de documentos; Instituições públicas; Acervos públicos. 


\section{Introdução}

No ano de 2003 o Centro de Memória e Documentação da Fundação Casa de Rui Barbosa - FCRB-CMD - , localizado na cidade do Rio de Janeiro, investiu na contratação de assessoria que permitisse à instituição reunir elementos para o esclarecimento sobre os diferentes aspectos que caracterizam a conversão digital de coleções/documentos fotográficos. As atividades na instituição se desenvolveram ao longo de oito meses, de março a dezembro.

Pouco depois, em 2004, na mesma cidade, foi a Divisão de Informação e Prospecção Tecnológica do Instituto Nacional de Tecnologia - INT-DIPT- que contratou assessoria com objetivos semelhantes, limitada, no entanto, à elaboração de material de apoio associado a um conjunto de palestras de atualização profissional, orientadas especificamente ao trabalho com documentos/coleções de textos impressos, predominantemente no formato A4. O conteúdo destes produtos constituiu-se de elementos que viessem a criar condições de discernimento entre profissionais de diferentes setores (secretaria, arquivo, biblioteca, informática) acerca da metodologia de operações de digitalização orientada à preservação. As atividades duraram cinco dias.

Para uso exclusivamente interno de ambas as instituições, visando à atualização técnica de seus quadros de funcionários, foram elaborados diferentes guias de procedimentos básicos para a digitalização que abordassem aspectos da seleção, conversão e controle de qualidade.

Tanto o FCRB-CMD como a INT-DIPT privilegiaram a atualização técnica de suas equipes, com significativo interesse e participação dos servidores selecionados para a formação. Os grupos foram compostos por dirigentes de setores, fotógrafos, arquivistas, bibliotecários, engenheiros de sistemas, jornalistas, web designers, comunicadores, editores, entre outros profissionais. No caso da FCRB-CMD a formação foi complementada por visitas a grandes instituições públicas depositárias de coleções/documentos especiais, que realizavam atividades e/ou projetos de conversão de parte de seus acervos, e a uma empresa privada especializada na digitalização de grandes volumes de toda espécie de documentos, com importantes clientes nas esferas pública e privada.

contato inicial com os dirigentes e técnicos que participariam da formação básica já havia deixado clara a necessidade de que fossem oferecidos conteúdos associados a procedimentos adequados à tomada de decisões sobre o quê e como selecionar documentos e coleções para a conversão digital.

Como se poderá notar, apesar de não se tratar exatamente de um relato de pesquisa científica, mas do resultado de assessorias técnicas, o artigo relata aspectos que consideramos relevantes, acreditando que possam ser úteis no contexto de experiências semelhantes. É importante atentar para o fato de que o texto remete a procedimentos de seleção de documentos para digitalização, e não especificamente sobre procedimentos relativos à conversão digital propriamente dita. Talvez importe destacar que as atividades e resultados das assessorias aqui narradas tiveram sua origem e se basearam em pesquisa de doutoramento onde foram investigadas 16 instituições públicas na cidade do Rio de Janeiro. Nesse sentido, cremos configurar-se, no relato aqui realizado, uma aproximação entre técnica e ciência que favorece o aperfeiçoamento de operações prévias de seleção de documentos de acervos de instituições públicas que, de outra forma, poderiam tender ao desgaste de equipes, à adoção de 
procedimentos dispersivos, a resultados inconsistentes na conversão e ao desperdício de tempo e recursos, sempre tão escassos nas esferas públicas.

A seguir tecemos comentários de cunho introdutório à conversão digital de acervos públicos. Em seguida apresentamos um breve relato onde procuramos destacar elementos relevantes do trabalho desenvolvido na FCRB e no INT. Na seqüência, abordamos os principais pontos referentes ao tema da seleção de documentos, no contexto de projetos de conversão digital de acervos públicos. Concluímos apresentando comentários de ordem geral acerca do acesso remoto a versões digitais de acervos de instituições públicas.

\section{Breve comentárí sobre digitalização de acervos públicos '}

A reformatação digital de acervos públicos e sua conseqüente disponibilização para acesso irão, certamente, ao encontro das expectativas de um novo público. É natural que a implementação de sistemas digitais que ofereçam, através de novos canais de distribuição, substitutos visuais para os documentos depositados em arquivos, museus e bibliotecas, acarretem efeitos significativos à própria coleção e a seu uso, já que de espectador o usuário passa a participante. ${ }^{2}$

Dois caminhos são possíveis nesse contexto de mudanças tecnológicas: adquirir uma tecnologia visando à solução de um problema específico (aperfeiçoando, por exemplo, o acesso a conteúdos informacionais), ou adotála como uma opção de preservação, sendo necessário, nesse caso, um profundo e prolongado compromisso institucional. Qualquer das opções exige um entendimento dos propósitos da digitalização que nos habilite a tomar decisões acerca dos parâmetros do processo.

Há aspectos técnicos, por exemplo, que muitas vezes são abordados de forma conservadora. Um exemplo é o da captura ou digitalização do documento, que idealmente deve ser feita a partir do original. Esta sempre foi uma questão que gerou muitas polêmicas, várias vezes sem fundamento, entre os profissionais responsáveis pela guarda de originais fotográficos, por exemplo. Ester ( 1996) participa da opinião de que a captura deve ser feita a partir do original (seja um original em papel ou em filme) e não a partir de um negativo de segunda geração, já que isto implicaria numa significante perda de qualidade quando comparada a uma digitalização feita a partir do original. Se houver necessidade do uso de intermediários, deve-se limitar o número de gerações. Não se deve desperdiçar resolução utilizando-se fontes de captura inadequadas ao trabalho que visa ao acesso orientado à preservação. Devemos sempre proceder à captura de alta qualidade, já que usualmente são geradas múltiplas versões derivadas de uma imagem de alta resolução.

Mas não apenas questões técnicas são importantes. Há o aspecto cultural que envolve o acesso a documentos constituintes de acervos públicos, particularmente se pensarmos em documentação fotográfica, audiovisual ou sonora. Uma versão digital modifica este envolvimento, alterando em muito o uso do conteúdo destes acervos e sua própria característica intrínseca de valor simbólico, já que novos tipos de leituras e escritas coletivas tornam-se possíveis.

Nesse sentido, há a exigência de um esforço enorme para a organização dos grandes estoques de conteúdos informacionais do futuro, de forma a tornar viáveis usos mais adequados. Há, ainda, a necessidade de uma permanente atenção às questões relacionadas a recursos e fundos para a realização de
Reflexão teórica e aspectos técnicos relativos à conversão digital são tratados ampla e exaustivamente em Silva (2002), que apresenta vasta literatura sobre o tema; Kenney e Rieger (2000) também são fontes fundamentais para os aspectos técnicos da digitalização.

${ }^{2}$ Cf. Besser, 1996 
ajustes institucionais, já que as bibliotecas e arquivos terão de suportar, nesse período de transição, e ainda por um longo tempo, dois sistemas diferentes, o tradicional e o digital, cujos requisitos conflitantes, despesas e modificações necessárias poderão de fato ser difíceis de conduzir. A participação da equipe envolvida nos projetos será fundamental para o sucesso do empreendimento. Para isso serão necessários investimentos que possibilitem a aquisição de um elevado nível de competência técnica e de experiência que permitam o desenvolvimento de projetos e a execução das novas iniciativas a serem incorporadas. $\bigcirc$ treinamento e o crescimento profissional, por si só, já atuam favoravelmente junto aos técnicos como um verdadeiro incentivo à participação e, seguramente, constituem parte dos custos da institucionalização da preservação digital, que deverá prever o estabelecimento de novas responsabilidades para os membros da equipe. ${ }^{3}$ Estes aspectos foram incorporados por duas instituições públicas federais na cidade do Rio de Janeiro, cujas experiências permitiram reunir elementos que podem orientar a configuração de estratégias em outras instituições ou organizações que venham a realizar atividades ou projetos de conversão digital de seus acervos.

\section{CMID e DIPT: Aspectos observados nas instituiç̄ões}

Visando ao levantamento de elementos, limites e necessidades referentes a operações de digitalização, o trabalho desenvolvido no CMD gerou diferentes resultados: identificação de potenciais coleções que pudessem vir a ser selecionadas para a conversão digital em um projeto piloto, reconhecimento da infra-estrutura disponível, debate sobre direito de propriedade e de reprodução, revisão de conceitos, além da discussão acerca da postura limitadora de doadores de acervos pessoais no que se refere à reformatação digital e à distribuição eletrônica via internet.

Complementarmente, procurou-se estimular a prática de exercícios específicos de conversão digital de documentos de espécies variadas, segundo os procedimentos até então adotados na instituição. Desta forma foi possível avaliar posturas e opções estabelecidas no cotidiano profissional, corrigindo-as ou as aperfeiçoando.

Outro aspecto importante foi o incentivo ao desenvolvimento de um maior nível de exigência dos técnicos da instituição junto aos fornecedores de softwares de organização, catalogação, indexação e recuperação de documentos. Essas exigências caracterizam-se, por exemplo, pela indicação da necessidade de adaptação desses produtos, de forma que atendam às demandas de fato associadas à atividade que concretamente os técnicos desempenham, como a adequação de campos de formulários online mal projetados ou inexistentes, simplificação de interfaces, entre outros. Outro elemento caracterizador das atividades desenvolvidas no CMD foi o debate sobre formas de apresentação/disponibilização na web de versões digitais de documentos já organizados, catalogados e indexados, visando à recuperação simplificada, orientada ao leigo, ao usuário da internet (por ex., mostrar imagens do documento, antes dos seus registros de catalogação). De fato, alguns produtores/fornecedores desses softwares recebem tais sugestões como colaborações para o aperfeiçoamento de seus produtos, advindas da

${ }^{3}$ Cf. Allen (1998), Kenney e Conway (1998) e Miranda (1996). experiência dos profissionais que os utilizam para a organização documental e/ou informacional. Essa colaboração leva à conclusão de um outro aspecto 
importante para as instituições: antes da aquisição de qualquer produto específico (de base de dados, de catalogação) é preciso estar atento à redução de dificuldades para a migração do que já existe na instituição, quer seja entre sistemas operacionais diferentes, quer seja entre produtos de fabricantes diferentes para um mesmo sistema.

Com a intenção de exemplificar e registrar o nível de limitações técnicas que podem ser enfrentadas cotidianamente por técnicos que lidam com versões digitais de itens de coleções/documentos especiais em instituições públicas, selecionamos alguns problemas destacados pelos profissionais dos diferentes setores. Basicamente foram apontadas limitações observadas na relação com os usuários finais das coleções. Os exemplos de maior recorrência são os referentes à impressão de manuscritos e de fotografias destinadas ao atendimento de solicitações de consulentes. Quatro principais pontos foram os mais destacados pelos servidores públicos:

a) Equipamento: pequena capacidade de armazenamento em discos rígidos, memória RAM disponível inadequada para a tarefa, scanners impróprios;

b) Mídia de impressão: o suporte (papel) utilizado não é adequado à impressão de arquivos de imagens, sejam fotografias ou manuscritos, acabando por provocar elevado consumo de tinta. Os papéis devem ser os adequados, para que sejam alcançados os melhores e mais econômicos resultados;

c) Operações remotas: impressão remota (comando numa sala e impressão em outra), sem o acompanhamento do técnico que emitiu o comando para a tarefa (ou de um outro responsável por este acompanhamento), resultando na total inadequação da versão impressa, no desperdício de tinta, de papel, em problemas nas cabeças de impressão dos equipamentos. Há que se destacar que a opção por cartuchos alternativos aos produtos originais destinados a impressoras jatos de tinta também pode acarretar em problemas de qualidade de impressão;

d) Reprodução fiel de cores do suporte original: é preciso que se decida sobre a necessidade real de se reproduzir à tonalidade do papel utilizado como suporte do documento original manuscrito (já submetido ao envelhecimento natural) quando se atende a solicitações de consulentes desse tipo de documentação: até que ponto o excessivo consumo de tinta que simula a cor do suporte original envelhecido de um documento, cujo conteúdo principal é textual, é relevante para o consulente? Se for relevante, o valor cobrado pelo serviço de impressão a cores deveria ser diferenciado do de uma versão bitonal.

Naturalmente alguns desses itens podem ser facilmente sanados com uma formação adequada. Nesse sentido, a participação de técnicos em oficinas de gerenciamento de cor, impressão e de manutenção de bases de dados de imagens - decisão acertada da direção do $\mathrm{CMD}^{4}$ - é o melhor procedimento a ser adotado. Outro aspecto de grande relevância são as visitas a outras instituições públicas que desenvolvem, internamente, propostas de digitalização de parte de seus acervos e a empresas com atuação no mercado de guarda, microfilmagem e digitalização de documentos. $\mathrm{Na}$ experiência desenvolvida no CMD, visitas ao Arquivo Nacional e à Biblioteca Nacional - bastante
${ }^{4}$ À época o CMD era dirigido pela Dra. Ana Maria Pessoa dos Santos, que viabilizou a participação de um técnico da instituição em curso realizado em laboratório de digitalização da Escola de Belas Artes da Universidade Federal de Minas Gerais. 
detalhadas com relação aos aspectos técnicos, às capacidades e limitações, aos problemas e soluções - mostraram-se eficazes, no que se refere ao interesse do grupo de técnicos e às informações que obtiveram dos anfitriões, resultando em grande êxito quanto à ampliação da compreensão dos limites e soluções vivenciados.

Também deve ser viabilizada a possibilidade de conhecer o cotidiano de empresas privadas de grande porte do mercado de guarda, de microfilmagem, de digitalização de documentos, de desenvolvimento de sistemas de recuperação de registros e conteúdos informacionais, entre outros produtos e serviços. Essa foi mais uma decisão correta do CMD, que permitiu a seus técnicos conhecerem ambientes profissionais com:

a) equipes compostas por mais de 30 pessoas para a digitação de documentos manuscritos financeiros e administrativos;

b) digitalizadoras de microfilmes $16 \mathrm{~mm}$, operando a 63 quadros por minuto, com ajustes automáticos da imagem e do quadro;

c) operações de digitalização de documentos administrativos textuais impressos, com alta capacidade de produção.

Esse tipo de experiência causa impacto positivo nos visitantes, permitindo o estabelecimento de comparações seguras entre o cotidiano vivenciado profissionalmente na esfera pública e aquele observado nas abordagens e métodos de trabalho da esfera privada, até então desconhecidos.

O DIPT, de certa forma, beneficiou-se da experiência realizada no CMD. ${ }^{5}$ Embora com objetivos e características diferenciadas, e com um investimento de tempo e de recursos no DIPT incomparáveis aos adotados pelo CMD, as atividades desenvolvidas em ambas as instituições tiveram como elemento comum um curso de atualização técnica sobre digitalização de acervos. No caso do CMD, tratava-se de metodologia para tomada de decisões acerca de procedimentos de conversão de acervo fotográfico, no contexto da criação de um futuro Núcleo de Digitalização de Documentos. ${ }^{6}$ No DIPT, o caso era de uma atualização técnica, configurada em cinco palestras que abordassem

${ }^{5}$ Foi a direção do CMD que sugeriu ao DIPT a contratação de assessoria.

${ }^{6} \mathrm{O}$ 'Anteprojeto de Criação do Núcleo de Digitalização de Documentos' foi um dos produtos resultantes da assessoria, juntamente com os guias de procedimentos básicos de 'Seleção de Documentos e Coleções para Conversão Digital', de 'Conversão Digital de Documentos e Coleções' e de 'Controle e Revisão de Qualidade de Versões Digitais de Documentos e Coleções'. Recentemente estes guias foram reunidos em um único manual, publicado pela Editora da Universidade Federal da Bahia (EDUFBA). Ver Silva, 2005.

${ }^{7}$ O projeto foi de autoria da Dra. Cícera Henrique da Silva, então funcionária do DIPT, e intitulava-se 'Produção Científica e Tecnológica do INT: sua contribuição para a compreensão da C\&T no Brasil', aprovado pelo CT/NFRA/MCT/CNPq-03/ 2003. questões sobre tomada de decisões acerca de procedimentos de conversão de acervo de textos impressos, no âmbito de projeto aprovado pelo CNPq. ${ }^{7}$

Em ambas as instituições a seleção de documentos para conversão foi um ponto de destaque da formação profissional. Com o objetivo de reunir, de forma didática, elementos que venham a ser úteis em outros contextos institucionais onde projetos e/ou atividades de digitalização de acervos venham a ser desenvolvidos, abordaremos, a seguir, aspectos relevantes sobre o tema da seleção de documentos.

\section{Seleção de documentos para conversão digital}

O processo de seleção de coleções/documentos para conversão digital pode ser bastante similar a outros processos de seleção já conhecidos de profissionais de bibliotecas, arquivos e museus, como seleções prioritárias para conservação, seleção de conteúdos para exibição ou publicação, seleção para tratamento em função de demanda de usuários, seleção de documentos com restrições legais de reprodução ou acesso, etc. Processos de seleção sempre envolvem indicações, avaliações e prioridades, as quais não podem ser decididas 
por uma única pessoa. $O$ primeiro passo, portanto, deve ser o estabelecimento de uma comissão para o processo de seleção.

\subsection{Constituindo uma Comissão de Seleç̧ão:}

Serão responsabilidades dessa comissão:

a) as indicações iniciais de coleções ou itens para a conversão digital;

b) posteriormente a comissão avaliará quais documentos deverão de fato permanecer no conjunto inicialmente destacado para conversão; c) em seguida deverão ser estabelecidas prioridades baseadas no valor, uso e risco dos materiais.

Uma comissão de seleção para conversão digital deve ser constituída por:

a) membros da instituição que conheçam a missão e os objetivos da instituição;

b) membros da instituição que conheçam a política local de desenvolvimento de coleções;

c) doadores e responsáveis pela organização e guarda da coleção, que a conheçam em profundidade;

d) pesquisadores especialistas em temas que caracterizem eventualmente um determinado projeto;

e) educadores especialistas em um determinado público que caracterize eventualmente o escopo de um projeto específico;

f) especialistas em digitalização, tais como fotógrafos ou membros da equipe com conhecimento adequado;

g) especialistas em conservação e preservação;

h) bibliotecários, arquivistas e museólogos/curadores;

i) pesquisadores experientes no trabalho com recursos online;

j) advogados.

É importante que a comissão conheça os objetivos, planejamentos, público alvo, avaliações e critérios de seleção que tenham caracterizado outras iniciativas ou projetos desenvolvidos por outras instituições. Mesmo quando um processo de seleção tenha sido orientado a exposições/exibições dos originais ou a publicações, que são casos muito específicos, pode haver componentes que sugiram abordagens de seleção para conversão digital.

\subsection{Cautela experiência:}

Quando ainda não se adquiriu o expertise de implementação de projetos de conversão digital, devem-se evitar documentos:

a) de grandes dimensões ou de formatos variados/não usuais;

b) com amplas variações tonais;

c) a cores;

d) documentos manuscritos complexos ou pouco legíveis. 
Projetos iniciais deveriam ater-se a materiais:

a) com tamanhos e tipos relativamente padronizados;

b) com contrastes normais;

c) com dimensões máximas próximas ao formato A4, como textos impressos, ou mesmo ampliações fotográficas originais com alta definição e contrastes;

d) sobre os quais a instituição detenha os direitos de propriedade ou as licenças necessárias à sua utilização/reprodução/disponibilização em suportes/formatos diversos (é necessário um completo entendimento sobre os direitos de uso e de propriedade);

e) sobre os quais não venham a recair restrições devido a aspectos relativos a privacidade, publicidade, difamação, obscenidade, ou outros fatores declarados pelos doadores;

f) que estejam submetidos a altos riscos de perda, mas que sejam suficientemente estáveis, ou que já tenham sido reproduzidos fotograficamente de forma adequada, para serem escaneados sem danos;

g) mais freqüentemente solicitados;

h) únicos na instituição.

Formulários podem ser idealizados para facilitar a equipe, os pesquisadores ou a comissão nas tarefas de indicar coleções/documentos a serem convertidos e de avaliar/identificar quais não deveriam ser digitalizados. Estes formulários poderiam estar disponíveis nas salas de pesquisa ou de consulta a todos os interessados que tenham familiaridade com o acervo ou com alguma coleção em particular. A decisão final será responsabilidade da comissão de seleção. Considerando a inexistência de uma estratégia já implementada de conversão digital que privilegie e assegure a preservação digital, não se deve adotar a opção do descarte do original a ser convertido. Se a opção for por preservar, deve-se microfilmar adequadamente os originais, ou então microfilmar suas versões digitais.

\subsection{Motivaç̃̃es para a seleçãa:}

Basicamente são três as motivações para a seleção: desenvolvimento da coleção, preservação/arquivamento e aperfeiçoamento do acesso. A motivação pode ser dirigida à coleção original ou à versão digital que será criada. Deve-se levar em consideração que quando o processo de seleção vai ao encontro dos interesses dos órgãos de fomento, a conversão pode gerar prestígio institucional.

\subsubsection{Motivação dirigida à coleção original:}

a) Desenvolvimento da coleção:

I. quando visa a atender as necessidades informacionais dos consulentes da instituição, não só internamente como via web;

2. preferencialmente deve ter o apoio/aval/acordo de uma ou mais comunidades que pesquisam na instituição. 
b) Preservação/arquivamento:

I. quando existem riscos de perda ou dano.

\subsubsection{Motivação dirigida à versão digital:}

a) Desenvolvimento da coleção:

I. quando adiciona valor informacional à documentação;

2. quando facilita maiores circulação e funcionalidade.

b) Preservação/arquivamento:

I. quando a instituição considera-se apta e disposta a manter a versão digital da coleção ao longo do tempo (protegendo contra desastres naturais, falhas mecânicas, corrupção intencional dos arquivos) e a acompanhar as mudanças tecnológicas (renovação, migração), de forma a assegurar o contínuo acesso a materiais de importância permanente para a pesquisa;

2. exige altas resoluções espaciais/tonais;

3. o conteúdo informacional deve ser capturado adequadamente, sem danos ao original, de forma que sirva como cópia de uso, em substituição ao uso do original.

c) Acesso:

I. quando o conteúdo informacional pode ser integrado aos serviços da instituição;

2. deve ser viabilizada a distribuição com velocidade razoável via redes;

3. soluciona problemas técnicos associados ao acesso aos originais (p.ex., fragilidade);

4. metadados (p.ex., identificação, indexação, captura, proveniência) devem estar previamente organizados;

5. deve ser estudada a possibilidade de autenticação das versões digitais, de forma que os usuários possam ter certeza de estarem utilizando um documento legal.

\section{Considerações finais}

Resumidamente, para que os resultados e produtos gerados durante as assessorias adviessem da participação ativa de todos, o que fizemos foi dar início à proposta a partir da formação de um grupo de trabalho composto por dez técnicos. Começamos o trabalho procurando fazer o levantamento de elementos, limites e necessidades referentes a operações de digitalização e discutindo questões referentes a potenciais coleções que pudessem vir a ser selecionadas para a conversão digital em um projeto piloto. Promovemos certa concentração em torno das questões de direito de propriedade e de reprodução, visando ao 
encaminhamento de uma solicitação de revisão de conceitos e da postura limitadora de doadores no que se refere à reformatação digital e à distribuição eletrônica via internet. Realizamos exercícios específicos de conversão digital de documentos de espécies diferentes, segundo os procedimentos até então adotados, com a intenção de desenvolver procedimentos comparativos após a eventual adoção de operações mais adequadas de digitalização. Procuramos estimular um maior nível de exigência dos técnicos das instituições junto aos fornecedores de produtos associados a softwares, bases de dados, catalogação, indexação e recuperação de documentos, antes da aquisição de qualquer produto específico, visando à redução de dificuldades para a migração, quer seja entre sistemas operacionais diferentes, quer seja entre produtos de fabricantes diferentes para um mesmo sistema.

O que é preciso destacar, no entanto, é que o ponto chave para a avaliação de qualquer fator associado a operações de conversão digital de acervos públicos não está na tecnologia especificamente, mas na sua necessária relação com a missão da instituição. Isso torna improcedentes quaisquer julgamentos realizados isoladamente.

A opção das instituições pelos usuários prioriza efetivamente a liberação de conteúdos informacionais com acesso ampliado para além dos limites da instituição, tornando parte das coleções acessíveis na world wide web. No entanto, serão fundamentais, para um tratamento arquivístico, a identificação, a autenticação e a preservação da integridade dos registros disponibilizados na internet, de forma que mantenham conteúdo e forma originais. Qualquer ausência ou inadequação no processamento da representação da informação (na sua manutenção) pode provocar a inacessibilidade ao conteúdo. Aprender a selecionar adequadamente entre as técnicas de produção de cópias é um aspecto essencial no treinamento de arquivistas, bibliotecários e curadores voltados às questões do acesso e da preservação. A opção pelo procedimento adequado deve basear-se na permanência, no custo, no tempo, na qualidade e no uso da cópia pretendida. Além disso, a representação digital da informação traz à tona questões éticas, legais e sociais e ainda as difíceis questões da propriedade intelectual, da proteção da confidencialidade e da privacidade.

A seleção de documentos que serão convertidos constitui este complexo processo de tomada de decisões, que será contínuo. É errôneo imaginar que todos os documentos de uma determinada coleção ou acervo virão a integrar uma base de dados para acesso remoto. $\bigcirc$ grande número de itens obriga a uma decisão cuidadosa sobre o quê digitalizar, baseada num profundo conhecimento acerca da natureza da coleção e no compromisso ético de contemplar as necessidades informacionais do público.

É importante registrar que, com o advento da digitalização, a evolução dos suportes e das modalidades de reformatação documental, faz-se necessária uma reavaliação de abordagens e procedimentos cotidianos. Por esse motivo destacamos alguns aspectos observados no trabalho desenvolvido com as instituições.

A aquisição de um scanner de mesa apropriado, preferencialmente em formato $A 3$, acrescido de unidades de digitalização de transparências, e de um computador configurado para o trabalho com imagens de documentos (incluindo dispositivo de gravação de CD's/DVD's), é importante para que os 
setores responsáveis possam cumprir minimamente novas atribuições cotidianas inerentes à conversão digital. Outro ponto importante (particularmente para as instituições depositárias de acervos iconográficos) refere-se à constituição de um pequeno estúdio fotográfico, com os equipamentos (digitais e/ou analógicos) adequados ao trabalho de reprodução de originais planos e de pequenos objetos de museu.

De nada adiantam procedimentos adequados de conversão digital se os originais estiverem submetidos a condições inadequadas de conservação e preservação. Assim, deve-se atentar para a climatização de ambientes de guarda e/ou reservas técnicas das instituições, bem como de um controle regular de temperatura e umidade relativa. Atualmente, em muitas instituições, materiais de constituições físicas variadas, que exigem ambientes e controles específicos, estão reunidos num mesmo espaço: é importante inventariar os materiais depositados na reserva e estudar soluções para problemas do gênero. Da mesma forma, o atendimento às solicitações de consulentes que demandam acesso aos materiais pode trazer problemas para os documentos, se forem retirados do ambiente de reserva sem o devido procedimento orientado à conservação/preservação documental. É importante que as instituições estejam atentas ao problema e invistam na criação de instrumentos (organização e métodos, impressos, procedimentos básicos) para adequar os fluxos não apenas às consultas e às necessidades de usuários, mas também às necessidades técnicas da documentação.

Sugerimos que os interessados por aspectos associados à reflexão teórica acerca da conversão digital (particularmente de acervos fotográficos públicos) consultem Silva (2002), que também reúne elementos do âmbito da técnica; os que pretendem inteirar-se sobre aspectos operacionais referentes à digitalização de acervos de diferentes espécies (textos, mapas e imagens fixas), talvez encontrem em Silva (2005) uma boa fonte introdutória.

Para concluir, registramos que a rica experiência de mão dupla que conseguimos estabelecer, particularmente no CMD (devido ao tempo investido ter sido mais prolongado do que no INT), caracterizou-se pelo regular e gradativo acréscimo de interesse do corpo técnico. Certamente isso resultou do forte compromisso da direção do CMD, que irrestritamente estimulou e apoiou a realização de cinco reuniões com a gerência, quatro reuniões com a equipe, três visitas técnicas (uma delas realizada apenas pelo consultor, com o objetivo de estabelecer contatos com a UFMG que viriam a mostrar-se eficazes para o reforço das relações entre a FCRB e a universidade), além de manter constante contato (troca de 49 mensagens eletrônicas e oito cartas impressas encaminhado documentos com a consultoria), que acabaram por resultar em um anteprojeto, três relatórios, um seminário, três guias de procedimentos básicos e uma mesa redonda. Se algum sucesso foi alcançado, são particularmente devidos às instituições, representadas por seus gestores, e a seus técnicos, que de forma ativa e compromissada contribuíram, com grande interesse, para a realização das metas estabelecidas. Somente assim, com o investimento e o compromisso das instâncias superiores das instituições e com o empenho do corpo técnico, bons resultados poderão ser alcançados com relação à preservação das versões digitais dos acervos públicos. 


\section{Basic procedures for selection of documents for digital conversion: elements of professional training in sections of two public federal universities}

This article comments on part of the results of technical consulting done at Centro de Memória e Documentação, Fundação Casa de Rui Barbosa (2003) and at Divisão de Informação e Prospecção Tecnológica, Instituto Nacional de Tecnologia (2004). The common element of the two consulting works was a technical training course on digital conversion of collections. The main aspects about selecting documents for digitization are discussed. It is shown that even renowned institutions face problems on professional training in digital conversion of collections.

Keywords: Digital conversion; Document selection; Public document collections.

\section{Referências}

AllEN, Nancy. Institutionalizing digitization. Collection Management/Special issue: Going digital: Strategies for access, presenvation, and conversion of collections to a digital format), v. 22, n. 3/4, p. 217-223, 1998.

BESSER, Howard. The changing role of photographic collections with the advent of digitization. Pappers. 1999. Disponivel em: http://www.gseis..ula.eddu/ $\sim$ howard/Papers/garmil-eastman.httml. Acesso em 24. set. 2006 .

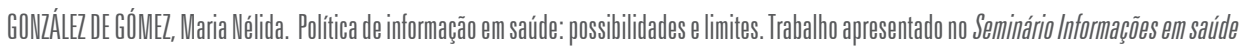
no Nordeste: proposiçöes à formulą̧ão de una polifica. Secretaria de Saúde de Pernambuco, 25 e 26 de nov., Recife, PE ccópia fornecida pela autora; impressa a partir de versão digitall), 1998.

KEWWEY, Anne; BlEEEER, Oya (Ed.PPrincipal Authors). Moving Theory into Practice: Digital Imaging for Libraries and Archives. Mountain View, CA: Research Libraries Group, 2000, 189 p.

KEWNEY, Anne; CONWAY, Paul. From analog to digital: extending the preservation tool kit. Collection Managemement(Special issue: Going digital: Strategies for access, preservation, and conversion of collections to a digital format), v. 22, n. 3/4, p. 65.79, 1998.

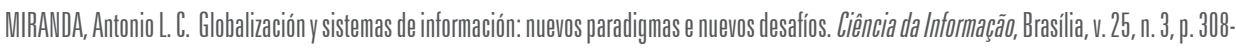
313 , set.dez, 1996 .

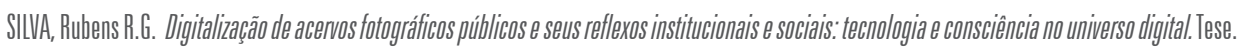

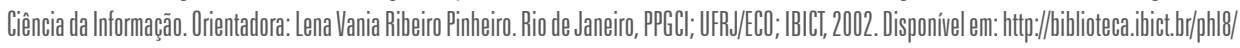
anexos/rubenssilva52002.pdf. Acesso em: 24. set. 2006.

SILUA, Rubens R.G. Manual de Digitalização de Acervos: Textos, Mapas e Imagens Fixas. Salvador: EDUFBA, 2005. 